\title{
Preventive Therapy for Cancer
}

\author{
Jack Cuzick, PhD, FRS \\ John Snow Professor of Epidemiology, \\ Centre for Cancer Prevention, Wolfson Institute of Preventive Medicine \\ Queen Mary University of London
}

\begin{abstract}
Address for correspondence:
Wolfson Institute of Preventive Medicine

Charterhouse Square

London EC1M 6BQ

United Kingdom

Email: j.cuzick@qmul.ac.uk
\end{abstract}

Summary. Therapeutic cancer prevention is a new field that can learn a lot from the successes in the prevention of cardiovascular diseases. While weight control and physical activity are important for both, preventive therapies have much to add. Low dose aspirin for cancer prevention stands out as the most important agent in terms of population benefit, and should be offered to most people above the age of 50 years who do not have hypertension or risk factors for gastrointestinal bleeding. Universal vaccination against the human papillomavirus, ideally with the 9-valent vaccine, also offers clear benefits for the whole population if given before infection occurs (typically at age 12-14y). Other therapies, notably anti-oestrogen drugs for breast cancer prevention need to be targeted to high risk groups to maintain a favourable benefit-risk ratio. Better algorithms for their identification and better platforms for reaching them, eg. as part of a screening visit remain a key priorities if the discoveries made to date are to have an important impact on public health. Many other promising agents have been identified, often as components of food, but negative experiences with beta-carotene and vitamin $\mathrm{E}$, indicate that they need rigorous evaluation before acceptance.

Introduction. Cancer prevention is a large field comprising lifestyle changes to reduce risk, screening interventions to detect early lesions and preventive interventions aimed at more actively interrupting the carcinogenic pathway. Here we only consider the later. Compared to cardiovascular disease where preventive treatments are firmly established, the development of therapies to prevent cancer is still in its infancy. This in part reflects the fact that cancers 
are more heterogeneous and biologically complex than cardiovascular diseases, and causal pathways are less well understood. Good biomarkers for identifying individuals at increased risk for specific cancers are missing and even less is known about predictive factors for response to specific treatments.

The balance of risks and benefis is also inherently more challenging for preventive than for therapeutic interventions. Only a small fraction of the apparently healthy people who receive a preventive treatment would develop the specific type of cancer being targeted and lack of cancer is not apparent at an individual level, whereas all will incur some risk of side effects which are identifiable on an individual basis. This also leads to challenges in evaluating new agents as trials need to be larger in order to have enough endpoints points, and also longer as preventive effects often take more time to appear, as early stages of the carcinogenic process are targeted. Fear of cancer also has a greater impact on the human psyche leading to unsupported claims and wishful expectations for preventive efficacy for a plethora of unproven agents.

Here I review interventions for which there is good evidence of efficacy, those with promising but not fully convincing findings, and those for which there is a substantial amount of evidence of no benefit and in some cases even harm. Assessments are my subjective personal views based on the available data, but are not formal reviews such as those conducted by IARC, NICE or the USPSTF, which are only available for a limited number of agents. However, they are cited when available. 


\section{Effective Agents}

Surgery. Prophylactic surgery is an appropriate option for a small number of cases where the risk of disease (usually genetically based) is strong - typically above $50 \%$. There are two notable examples: colectomy for individuals with polyposis coli which is caused by a mutation in the apc gene and occurs in about 1 in 7000 to 23000 people depending on the population ${ }^{1,2}$. About $25-30 \%$ of these mutations are thought to be de novo with no affected family members. Surgery often takes place before age $25 y$ at which time, a large number of polyps are already present, and is virtually $100 \%$ effective if undertaken before cancer is present. The other wellknown example is women with a mutation in the BRCA1 or BRCA2 gene, which gives rise to a greatly increased risk of breast cancer (about $60 \%$ lifetime risk) and ovarian cancer (55\% for BRCA1 and $16.5 \%$ for BRCA2) ${ }^{3}$. Removal of the ovaries around age $35-40 y$ is common for BRCA1 and up to 5 years later for BRCA2. It not only eliminates ovarian cancer but also reduces breast cancer risk by about half ${ }^{4}$, whereas bilateral mastectomy eliminates $90-95 \%$ of breast cancer risk ${ }^{5}$. There is increasing evidence that most ovarian cancers initially arise in the fallopian tubes and only removing them could prevent this disease, and would result in fewer side effects 6 . Mutation in other rare genes can also lead to consideration of prophylactic surgery, although it is important reserve this extreme option for the very highest risk women, as above as some of these mutations only carry at $20-30 \%$ lifetime risk.

Vaccination. Vaccination against the human papilloma virus is likely to have a major impact on cervical and some other cancers. Vaccination before infection has been shown to virtually eliminate persistent infection and precursor cervical lesions (CIN) due to the HPV types contained in the vaccine, but longer follow up is needed before an effect on cancer becomes apparent. Two vaccines have been widely used - Gardasil $^{7}$ containing virus like particles 
(VLPs) as antigens against HPV types 16 and 18, which cause cancer, as well as types 6 and 11 which protect against genital warts. Cervarix ${ }^{8}$ only contains VLPs for types 16 and 18 . Recently a new 9-valent HPV vaccine which contains VLPs against 31,33,45,52 and 58 as well as 6, 11, 16 and 18 has shown very high efficacy against all 9 types if given before infection ${ }^{9}$.

Infant vaccination against Hepatitis B in Taiwan, where it is the major causative factor for hepatocellular cancer, has led to a more than $60 \%$ reduction in this cancer below the age of $20 y^{10}$. The main reasons for failure were active infection in the mother and incomplete vaccination. Further follow up will be needed to see if this protection continues into adulthood. Preventing Hepatitis $C$ induced cancer remains a major challenge, as no effective vaccine has yet to be developed ${ }^{11}$ although expensive treatments are now available to clear infections ${ }^{12}$.

\section{Pharmacologic Drugs initially used for other purposes.}

The greatest impact on the field of preventive therapy has been the use of drugs initially developed for other indications. This approach has been especially effective for demonstrating the preventive effect of anti-oestrogenic agents for breast cancer and aspirin for the gastrointestinal cancers, and is likely to lead to further important discoveries. One further discovery is that oral contraceptives have been clearly shown to reduce the risk of ovarian cancer by $27 \%$ for ever use and more than $50 \%$ for 10 years or longer use ${ }^{13}$, although it is difficult to imagine how this might be used in a targeted way. 
Breast cancer. Breast cancer prevention has been facilitated by the fact that drugs evaluated for their ability to prevent recurrence of a breast cancer also provide reliable evidence for a preventive effect on new tumours in the contralateral breast. Table 1 shows a variety of agents that have been evaluated for primary prevention.

Tamoxifen was the first such agent to illustrate this. Based on data from the CRC-II adjuvant trial, Cuzick and Baum ${ }^{14}$ published the first report of a preventive effect for tamoxifen. A meta-analysis of 20 randomized clinical trials of five-year treatment with tamoxifen as adjuvant therapy in 15000 women documented an approximately one-third reduction in contralateral breast tumours ${ }^{15}$. Four prevention trials have subsequently confirmed this finding in high risk women without breast cancer (Table 1). Overall, these trials show a $38 \%$ reduction in breast cancer incidence ${ }^{16}$, resulting from a $50 \%$ reduction of oestrogen receptor positive breast cancers but no effect on oestrogen receptor negative tumours. These trials have shown that the protection from tamoxifen persists after stopping the medication. In fact, for the two trials with the longest follow up ${ }^{17,18}$, a greater reduction in breast cancer incidence was observed in the follow up period than during active treatment (cumulative risk $4.6 \%$ vs $6.3 \%$ in years $0-10 ; 3 \cdot 3 \%$ vs $6 \cdot 3 \%$ in years $10-20$ ), and this has persisted for 15 years after treatment completion (Figure1).

The two major side effects of tamoxifen are endometrial cancer and venous thromboembolism. (Table 2). Endometrial cancer was increased by approximately 2.5 fold above the baseline rate of about 60 per 100000 per year at age 60, whereas venous thromboembolism was found about twice as often in the tamoxifen arm compared to placebo. Recent reports have shown that the excess of thromboembolic events is limited to the active treatment period, whereas the excess of endometrial cancer appears to continue after cessation. Less serious but more common side effects of tamoxifen include vasomotor symptoms such as hot flushes, night sweats and gynecologic symptoms such as bleeding and uterine polyps $^{19}$. Topical formulations of tamoxifen metabolites applied directly to the breast are now under study with the hope that the local does will be high enough to maintain its preventive effects, but the systemic dose will be reduced enough to limit its side effects ${ }^{84}$. Tamoxifen has now been approved for 
use in breast cancer prevention for high risk women in the USA by FDA and recommended in the UK by NICE.

Three other selective oestrogen receptor modulators (SERMs) have now been evaluated in addition to tamoxifen. Raloxifene is a second generation SERM originally developed to prevent osteoporosis in postmenopausal women. It has oestrogenic effects on bone and lipid metabolism, and anti-estrogenic effects on the endometrium and breast tissue. Because of this tissue selectivity, raloxifene has fewer side effects than tamoxifen. Three trials have evaluated raloxifene as a preventive agent for breast cancer in postmenopausal women (Table 1) and all have shown efficacy. In the MORE trial a $65 \%$ reduction in breast cancer was found after 4 years of treatment, which led to its continuation as the CORE trial with breast cancer as a primary endpoint ${ }^{20}$, where a $50 \%$ reduction in breast cancer was seen. A second study known as RUTH ${ }^{21}$ evaluated the impact of raloxifene in women with increased cardiovascular risk as the primary endpoint and found a $44 \%$ reduced incidence of invasive breast cancer.

The STAR trial ${ }^{22}$ is the only randomized clinical trial that has directly compared raloxifene with tamoxifen. It found that the reduction in breast cancer risk from raloxifene was about $25 \%$ less than for tamoxifen. In contrast to tamoxifen, no excess of endometrial cancer or other gynaecological problems were observed. However like tamoxifen it was associated with an increase of thromboembolic events, although the magnitude of the increase appears to be smaller. While raloxifene is less effective than tamoxifen, it may be more acceptable for postmenopausal women, where it is already widely used for osteoporosis. Raloxifene has now been approved for use in breast cancer prevention for high risk postmenopausal women in the USA by FDA and recommended in the UK by NICE.

Two other SERMs (lasofoxifene and arzoxifene) have been investigated in osteoporotic postmenopausal women with reduction in fractures as the primary endpoint. The PEARL trial ${ }^{23}$ evaluated two doses of lasofoxifene vs placebo and based on 49 breast cancers incidence was significantly reduced by $79 \%$ with the higher $0.5 \mathrm{mg} /$ day dose when compared to placebo. Furthermore, although there was a significant increase in thrombotic events, lasofoxifene significantly reduced major 
coronary events, strokes and both vertebral and non-vertebral fractures and so it may be ideal for prevention, where the total benefit-harm balance is particularly important.

The GENERATIONS trial ${ }^{24}$ evaluated arzoxifene $(20 \mathrm{mg} /$ day) versus placebo in 9,354 postmenopausal women with osteoporosis (Table 1). It reduced all breast cancer events by $58 \%$ and vertebral fractures by $41 \%$, but increased the incidence of thromboembolic events, hot flushes, muscle cramps and gynecological events, as with other SERMs (except gynecologic events for raloxifene).

\section{Aromatase Inhibitors}

The third generation aromatase inhibitors (AI) anastrozole, letrozole and exemestane have been found to be more effective than tamoxifen for the treatment of oestrogen receptor positive breast cancer in postmenopausal women ${ }^{25}$ and are now routinely used for this indication. Contralateral breast tumours, a good surrogate for new cancers, were also reduced by a further $50 \%$ compared to tamoxifen in these trials $^{26}$.

Two large breast cancer prevention trials have reported on the use of AIs in high risk women without cancer. The MAP3 trial randomized 4560 postmenopausal women to receive either exemestane or placebo for 5 years. A $65 \%$ reduction of invasive breast cancers was seen ${ }^{27}$. No reduction was observed for ER-negative disease, but the effect on ER-positive disease was even greater $(\mathrm{HR}=0 \cdot 27(0 \cdot 12-0 \cdot 60)$, $\mathrm{P}<0 \cdot 001)$. No statistically significant differences were found between treatment arms for adverse events, suggesting a good benefit-risk profile. However, these conclusions are limited by the short follow-up period of only 35 months.

The IBIS-II trial compared anastrozole to placebo in postmenopausal women at increased risk of breast cancer $^{28}$. After a median of 5 years of follow-up a highly significant $53 \%$ reduction of invasive breast cancer and DCIS combined (primary endpoint) was seen (HR $=0 \cdot 47,95 \%$ confidence interval $(0 \cdot 32$ 0.68), $\mathrm{P}<0.0001$ ), which was similar to the results reported in the MAP3 trial. For oestrogen receptor positive invasive cancer the reduction was $58 \%(\mathrm{HR}=0.42(0 \cdot 25-0 \cdot 71), \mathrm{P}<0.001)$, but as in the MAP3 
trial no effect was found for ER-negative breast cancer. Vasomotor and musculoskeletal side effects were increased with anastrozole, but only by $10-15 \%$, and these adverse events were also reported by many women receiving placebo. Thus most of these events were not attributable to anastrozole, but reflect a high incidence of them for all women in their early postmenopausal years. This illustrates the need to have a placebo arm to accurately assess subjective side effects. The risk of fractures was slightly but non-significantly increased by $11 \%(8.5 \%$ vs $7 \cdot 7 \%)$ for anastrozole. This was much less than the $50 \%$ increase seen in a previous adjuvant trial ${ }^{29}$, mostly likely due to the use of bone density (DXA) scans at entry, and appropriate bisphosphonate prophylaxis for women with low bone density. Blinded long-term follow-up is continuing in IBIS-II, so that the long-term efficacy and side effects of anastrozole can be evaluated.

Overall, the reported reductions in breast cancer incidence for both exemestane and anastrozole were larger than those seen for tamoxifen or raloxifene, and indicate that these two drugs are an attractive option for breast cancer prevention in postmenopausal women at increased risk of the disease. NICE have recently issued draft guidelines for consultation for the use of anastrozole in postmenopausal women in the UK (https://www.nice.org.uk/guidance/GID-NG10010/documents/short-version-ofaddendum). For premenopausal women the only current option remains tamoxifen.

None of these anti-oestrogen agents have had any impact on oestrogen receptor negative breast cancer, which remains an unmet need.

\section{$\underline{\text { Aspirin and other NSAIDs }}$}

There is now overwhelming evidence for an approximately one-third reduction in colorectal cancer incidence and mortality from long term regular aspirin use ${ }^{30}$. Beneficial effects of a similar size have been seen for oesophageal and gastric cancers, and smaller, less convincing 5-15\% reductions for lung, breast and prostate cancers (Table 1) have also emerged over the 
past several years ${ }^{28,31,32}$. There is also a suggestion of a small effect also for ovarian cancer, but this is still uncertain. There appears to be little or no effect on other major cancer sites including pancreatic, endometrial, and haematopoietic tumours. Long term use of about 10 years was estimated to reduce overall cancer incidence by about $10 \%$ in men and $7 \%$ in women, and overall cancer mortality by $13 \%$ in men and $9 \%$ in women ${ }^{28}$. Gastrointestinal and cerebral bleeding are the most important harms associated with aspirin use, and their risk and fatality rate increase with age ${ }^{33}$. Use of prophylactic aspirin in the general population aged $50-65 y$ is likely to be beneficial when the reduction in cancer and cardiovascular disease and excess bleeding are all considered. For example for 100 men aged 55y taking low dose aspirin for 10 years, Cuzick et $\mathrm{al}^{28}$ estimated that over the next 15 years there would be $2 \cdot 29$ fewer cancers, myocardial infractions and strokes and 0.49 more gastrointestinal bleeding events. For women the numbers were 1.32 and 0.25 resp. In terms of deaths in the next 20 years, for men there would be 1.60 fewer deaths from cancer and heart disease and $0 \cdot 17$ more from GI bleeds and strokes. For women these numbers were 0.82 and $0 \cdot 11$, resp. Both benefits and harms increase with age in men and women. Thus the benefit-risk ratio is highly favourable for the general population and is about 5:1 for serious events and at least 7:1 for deaths. This is likely to increase with further treatment duration and follow up. It is also clear that only a small proportion of the population will benefit and identifying which individuals are most likely to do so would allow treatment to be more focussed.

The effects of daily aspirin on cancer incidence are not apparent until at least 3 years after the start of use (Figure 2), with a relative incidence reduction after that time for all cancers of about $24 \%{ }^{34}$, and some benefits appear to be sustained for several years after treatment cessation in long-term users. Relative reductions in cancer incidence appear to be similar in men and women $^{34}$, although data are less extensive for women, and men have a higher incidence of the cancers reduced by aspirin, leading to greater absolute reductions. Two trials of alternate day 
use of 100mg - the Women's Health Study (WHS) ${ }^{35}$ and the Physicians' Health Study (PHS) did not show any cancer reduction within 10 years of follow-up, although a $43 \%$ reduction in colorectal cancer after 10 years has been observed in the $\mathrm{WHS}^{35}$. No differences between low and standard doses of aspirin have been observed either for efficacy or side effects, but there are no direct comparisons. Higher doses above $325 \mathrm{mg} /$ day do not appear to confer additional benefit but do increase toxicities.

The impact of aspirin on cancer mortality appears to be larger than for incidence ${ }^{36}$. The mechanisms by which aspirin prevents cancer incidence and mortality are poorly understood. Rothwell et al ${ }^{30}$ suggested that the greater effect on mortality is due to a reduction in metastatic spread, possibly through a platelet mediated mechanism, with benefits both before and after the diagnosis of cancer ${ }^{37,38}$. Trials are underway to examine aspirin as an adjuvant treatment for individuals with colorectal, gastric, oesophageal, breast and prostate cancer ${ }^{39}$. A recent review by the US Preventive Services Task Force (USPSTF) has given limited support for a preventive effect of aspirin on colorectal cancer incidence and possibly mortality ${ }^{82}$.

Data on other NSAIDs such as ibuprofen, sulindac or celecoxib are less extensive and there are no trials with long term follow up, except for studies of colorectal adenomas. However observational studies have found similar overall effects on cancer incidence ${ }^{40,41}$.

\section{Agents with preliminary evidence for cancer prevention}


Evidence for a potential preventive effect comes from two main sources, with very different limitations and potential confounding factors. One source is epidemiologic cohort and casecontrol studies. These have the advantage of looking at exposure in human populations, but can only establish an association between exposure and reduced disease incidence. Confounding of the association by other concomitant exposures, lifestyle or socioeconomic factors is a challenging issue, and randomised prevention trials offer the only certain protection against this. While epidemiologic studies have provided some important leads, such as for aspirin and colorectal cancer, there are also some serious examples where epidemiologic studies have suggested a preventive effect which was later disproved in randomised trials are indicated below.

The other approach which has generated or supported preventive effects is mechanistic laboratory studies. While understanding mechanisms is very important, the main limitation here is that tissue culture or animal models cannot fully reproduce the human environment, and there are several examples where convincing evidence of a mechanistic effect in the laboratory has not translated into a preventive effect in humans.

Several compounds have demonstrated both epidemiologic and laboratory evidence for a preventive effect. Of these metformin, a drug used to treat type 2 diabetes, is among the most promising. Early interest was sparked by a study using the UK General Practice Research Database $^{42}$, suggesting a more than $50 \%$ reduction in breast cancer. That was followed by other studies from this resource suggesting reductions in ovarian cancer. However no other cancers were reduced. Concerns have been raised about potential confounding with diabetes and especially the other medications used for this condition ${ }^{43}$. In an overview of 65540 cancer cases in 47 studies of diabetic women, metformin was found to have a beneficial effect on a range of cancers leading to an overall $31 \%$ reduction in incidence and $34 \%$ reduction in 
mortality ${ }^{44}$. Some of the concerns raised previously were addressed in this review and some of the differences appeared to be related to differences in BMI and time related factors (adjusted incidence reductions $18 \%$ and $10 \%$, resp). Significant reductions were only seen for lung and liver cancer. This remains an active area of research and a range of mechanisms have been suggested for metformin's action including activation of the AMPK pathway or a direct effect on the insulin levels via the liver ${ }^{45}$.

There are a vast range of agents, many of which are food constituents or their derivatives, which have shown anti-cancer effects in laboratory systems but for which evidence in humans is lacking or very minimal. It is not possible to review them all here. The US National Cancer Institute has a long standing and active programme in evaluating such agents. They periodically publish a compendium of drugs undergoing evaluation as potential cancer-preventive agents ${ }^{46}$. Most of these are still being investigated in laboratory systems, but some are also undergoing early Phase 1 and Phase 2 studies ${ }^{47}$, where biomarkers are also being studied as early indicators of treatment response.

\section{Dietary components}

Many studies have suggested a protective effect of consumption of fruits and vegetables, with a stronger effect seen in vegetables ${ }^{48}$. Specific potential ingredients include sulphoraphane found in cruciferous vegetables ${ }^{49}$ and lycopene, which is particularly high in cooked tomatoes, but is also found in other fruits and vegetables. High tomato consumption was initially linked to reduced prostate cancer risk by Mills et $\mathrm{al}^{50}$. A recent overview found no overall effect but a suggestion it might protect against high grade or fatal disease ${ }^{51}$. 
A number of spices have also been proposed to have protective effects ${ }^{52}$. Curcumin which comes from turmeric has been most studied, but there is still very limited human data for cancer prevention ${ }^{53}$. Of the many hundreds of other compounds ${ }^{54}$, resveratrol, which mostly comes from red wine and berries ${ }^{55,56}$, green tea polyphenols ${ }^{57}$, and pomegranate ${ }^{58}$ have received much attention but again convincing human evidence of efficacy is lacking.

The evidence for a role of vitamin $\mathrm{D}$ with or without calcium is very mixed but overall there is currently no compelling evidence that it has an effect on any cancer site either for incidence or mortality $^{59,82}$.

\section{Agents that haven't worked}

Epidemiologic and laboratory evidence suggested a potential anti-cancer effect of Vitamin A, beta carotene and their analogues ${ }^{60,61}$. Despite randomised evidence of a benefit of beta carotene, vitamin E, and selenium in a severely deficient population in Linxian, China ${ }^{62}$, subsequent studies in the West have been negative. Two large studies of beta carotene in heavy smokers and asbestos exposed workers ${ }^{63,64}$ found it actually lead to increases in the incidence of lung cancer and Omenn et $\mathrm{al}^{63}$ found an increase in all-cause mortality. In an overview of all randomised trials of $\beta$-carotene Druesne-Pecollo et a ${ }^{65}$ confirmed an increase in lung cancer incidence, and also found an increase in gastric cancer and no significant effect on other cancers, either individually or overall.

Trials of vitamin E, and selenium, both of which were thought to have a beneficial effect on prostate cancer, have also been negative. In particular neither selenium nor vitamin $\mathrm{E}$ supplementation reduced the incidence of prostate cancer in the SELECT trial, in which prostate cancer was the primary endpoint. Klein et $\mathrm{al}^{66}$ reported that in 35533 men with a PSA 
of $4 \mathrm{ng} / \mathrm{mL}$ or less and a negative digital rectal examination, the incidence of prostate cancer increased by $17 \%$ with vitamin E supplementation. Other studies have not shown any effects of supplementation on the incidence of prostate cancer ${ }^{67}$, colorectal cancer ${ }^{68}$ or cause specific mortality ${ }^{69}$.

The use of $5 \alpha$-reductase inhibitors either for prevention or management of early prostate cancer has produced complex outcomes, with substantial reductions in low Gleason grade disease but an apparent increase in high grade cancers. The Prostate Cancer Prevention Trial (PCPT) ${ }^{70}$ investigated finasteride in men with low PSA $(\leq 3 \mathrm{mg} / \mathrm{mL})$ and no evidence of disease. After 18 years of follow-up, a 30\% (95\%CI 24-35\%) reduction was observed in all prostate cancers based on a $43 \%$ reduction in low Gleason grade tumours but a $17 \%$ increase in high grade (Gleason 7 or higher) cancers. No impact on death from prostate cancer was seen. Similar results were reported in the REDUCE trial ${ }^{71}$, which assessed dutasteride, another $5 \alpha$-reductase inhibitor, in a high-risk population of men with a PSA concentration between $2.5 \mathrm{ng} / \mathrm{mL}$ and $10 \mathrm{ng} / \mathrm{mL}$ and a negative initial prostate biopsy. After 4 years of follow-up, a $23 \%$ reduction in overall prostate cancer incidence was reported compared with controls who received placebo, but there was no effect on cancers with Gleason score 7 or higher, and an increase in Gleason 10 tumours. Although both drugs have a beneficial effects on benign prostatic disease, the apparent increase in risk of high-grade tumours is of major concern. It has been suggested that this may be a result of detection bias. An increase in the sampling accuracy of the prostate with the then common six-needle biopsy, because of smaller total prostate size after $5 \alpha$-reductase inhibitor therapy, has been offered as an explanation for this finding. Overall the evidence for a detrimental or protective effect on the incidence of high grade prostate cancer or prostate cancer specific site-specific mortality remains inconclusive ${ }^{72}$, and neither finasteride nor dutasteride have been approved by the Food and Drug Administration for cancer prevention. 
There has also been much interest in the role of statins for cancer prevention, but the overall evidence is largely negative ${ }^{73}$.

\section{Conclusions}

Despite its early stage of development, preventive therapy already has made important discoveries which have the potential to make useful reductions in cancer incidence. Of these low dose aspirin stands out as having the largest potential impact on the population at large. This is because it has a major impact on three common gastrointestinal cancers - colorectal, gastric and oesophageal, and potentially provides small reductions in 3 other major cancers lung, breast and prostate. In terms of relative overall importance for cancer prevention tobacco cessation remains the most important factor, and Parkin $^{74}$ have estimated that tobacco use is responsible for $19 \%$ of all cancers. However they have calculated that no other activity is responsible for more than $10 \%$ of cancers, and the estimate that between $7-10 \%$ of cancers could be avoided by taking a daily low dose aspirin for 10 years between ages $50-65 y$ with a larger $9-13 \%$ reduction for mortality ${ }^{28}$ makes this a key element of any cancer prevention strategy. Other preventive activities such as eating more vegetables, reducing obesity, and taking more exercise are much harder to achieve ${ }^{81}$, and obtaining the full cancer reduction benefit identified from controlling these factors is unrealistic. While we are a long way from achieving the full benefit of preventive therapy, widespread use of aspirin is likely to be more acceptable, and other more toxic agents can be targeted to high risk individuals where there is a greater possibility of acceptance. Clearly a strategy that uses both approaches is needed.

Several major challenges remain however. Key among these is to find ways to encourage more widespread use of agents with established utility. Uptake of tamoxifen in women at high risk of breast cancer is only $10 \%$ at best and much of this is due to a lack of knowledge and interest 
in prevention from health professionals. Aspirin has suffered from earlier recommendations from professional bodies against using it in the general population ${ }^{75}$. However these recommendations were based on comparing cardiovascular benefits to bleeding risks, and now need updating in view of the much larger benefits seen for cancer prevention than for cardiovascular disease. These have only appeared more recently, largely due to the fact that they were not apparent until after 3-5 years of aspirin use.

There are several areas where further work is needed to focus the use of prevention agents. Key among these is risk assessment. This is less critical for aspirin as benefits are for a range of cancers, and we still do not understand the mechanisms behind its cancer prevention effects. Knowing these may help to focus use on those most likely to benefit, but a more immediate need is to understand who is at greatest risk of bleeding side effects, so that avoidance of use or treatment predisposing factors such as helicobacter infection can be employed. For the use of anti-oestrogen agents to prevent breast cancer, serious side effects are more common and risk in the general population is lower so targeting therapies to high risk individuals is essential to achieve a favourable benefit-risk ratio. Classical factors as combined in risk scores ${ }^{76,77}$, mammographic breast density ${ }^{78}$ and a panel of individual SNPs that are common but individually have low predictive power but in combination appear useful ${ }^{79}$ all are useful in risk assessment. Finding the best way to combine these factors to produce a more comprehensive risk model is needed.

A similar need is to find biomarkers which not only accurately predict risk, but also response to treatment, as LDL cholesterol and blood pressure provide for cardiovascular disease. Changes in mammographic breast density have been shown to predict response to endocrine agents both in the preventive ${ }^{80}$ and adjuvant treatment settings, but 6-12 months of treatment is needed to detect this, and earlier markers of effect are desirable. 
There is still a long list of promising agents that need further investigation. Full scale prevention trials are expensive and require long term follow up. They probably are unavoidable for agents in which widespread use is proposed, but we need better biomarkers and greater understanding of mechanisms to ensure we target the large prevention trials on agents very likely to be effective.

We also need to integrate activities to promote preventive therapy with those to encourage a healthy lifestyle. Neither of these alone will eliminate cancer, and adoption of one does not obviate the need for the other. In this regard we need to better integrate preventive therapy with other activities. Linking it with screening, especially breast screening where women attend a dedicated screening centre, is an obvious but undeveloped approach. However, this will require specialist staff in the screening clinics to be effective. Consideration of renaming breast screening programmes as breast cancer prevention programmes has merit, especially as mammographic breast density is an important risk factor which needs to be combined with a risk assessment based on family history and other classical risk factors, and possibly including a SNP risk score from blood or saliva. Advice from a trained nurse about what can be done to lower risk not only for breast cancer but other cancers and diseases is also needed to make this effective.

In addition to developing and publicizing effective agents we also have an obligation to debunk claims for ineffective agents. Cancer is such an emotional issue that people can often be misled by unsubstantiated claims for prevention or cure and part of a programme for cancer prevention needs to also make clear when evidence for an effect is very limited, non-existent or even clearly negative.

Prevention has become an integral part of cardiovascular medicine where risk factors such as high cholesterol of hypertension have been raised to the level of diseases in their own right. 
Although preventive therapy for cancer is still in its early days, we have already identified agents which if fully used would have an important impact on incidence and mortality. Because of the site specific nature and mechanistic complexity of cancer, progress will be challenging but there are already sufficient leads to feel confident that more can be achieved.

Conflict of Interest. No external funding was used to carry out this work. The author is on Advisory Boards for Merck and Bayer, he is a consultant for Atossa and his institution receives research funding from AstraZeneca. 


\section{References}

1. Bisgaard, M.L., Fenger, K., Bulow, S., Niebuhr, E. and Mohr, J. (1994) Familial adenomatous polyposis (FAP): frequency, penetrance, and mutation rate. Hum. Mutat., 3, 121-125.

2. Half E, Bercovich D, Rozen P. Familial adenomatous polyposis. Orphanet J Rare Dis. 2009 Oct 12;4:22.

3. Mavaddat $\mathrm{N}$, Peock S, Frost $\mathrm{D}$ et al; Cancer risks for BRCA1 and BRCA2 mutation carriers: results from prospective analysis of EMBRACE. J Natl Cancer Inst. 2013 Jun $5 ; 105(11): 812-22$.

4. Guillem JG, Wood WC, Moley JF et al. ASCO/SSO review of current role of riskreducing surgery in common hereditary cancer syndromes. J Clin Oncol. 2006 Oct 1;24(28):4642-60.

5. Ludwig KK, Neuner J, Butler A, Geurts JL, Kong AL. Risk reduction and survival benefit of prophylactic surgery in BRCA mutation carriers, a systematic review. Am J Surg. 2016 Oct;212(4):660-669.

6. Dubeau L. The cell of origin of ovarian epithelial tumours. Lancet Oncol. 2008 Dec; 9(12):11917.

7. Ault KA; Future II Study Group. Effect of prophylactic human papillomavirus L1 viruslike-particle vaccine on risk of cervical intraepithelial neoplasia grade 2 , grade 3 , and adenocarcinoma in situ: a combined analysis of four randomised clinical trials. Lancet. 2007 Jun 2;369(9576):1861-8.

8. Paavonen J, Naud P, Salmerón J et al; HPV PATRICIA Study Group. Efficacy of human papillomavirus (HPV)-16/18 AS04-adjuvanted vaccine against cervical infection and 
precancer caused by oncogenic HPV types (PATRICIA): final analysis of a doubleblind, randomised study in young women. Lancet. 2009 Jul 25;374(9686):301-14.

9. Joura EA, Giuliano AR, Iversen OE et al; Broad Spectrum HPV Vaccine Study. A 9valent HPV vaccine against infection and intraepithelial neoplasia in women. $\mathrm{N} \mathrm{Engl} \mathrm{J}$ Med. 2015 Feb 19;372(8):711-23.

10. Chang MH, You SL, Chen CJ et al; Taiwan Hepatoma Study Group. Long-term Effects of Hepatitis B Immunization of Infants in Preventing Liver Cancer. Gastroenterology. 2016 Sep;151(3):472-480.e1.

11. Fung J, Lai CL, Yuen MF. Hepatitis B and C virus-related carcinogenesis. Clin Microbiol Infect. 2009 Nov;15(11):964-70.

12. Webster DP, Klenerman P, Dusheiko GM. Hepatitis C. Lancet. 2015 Mar 21;385(9973):1124-35.

13. Havrilesky LJ, Moorman PG, Lowery WJ et al. Oral contraceptive pills as primary prevention for ovarian cancer: a systematic review and meta-analysis. Obstet Gynecol. 2013 Jul;122(1):139-47.

14. Cuzick J, Baum M. Tamoxifen and contralateral breast cancer. Lancet. 1985 Aug 3;2(8449):282.

15. Early Breast Cancer Trialists' Collaborative Group (EBCTCG). Effects of chemotherapy and hormonal therapy for early breast cancer on recurrence and 15-year survival: an overview of the randomised trials. Lancet. 2005 May 14-20;365(9472):1687-717.

16. Cuzick J, Sestak I, Bonanni B, et al; SERM Chemoprevention of Breast Cancer Overview Group. Selective oestrogen receptor modulators in prevention of breast cancer: an updated meta-analysis of individual participant data. Lancet. 2013 May 25;381(9880):1827-34. 
17. Powles TJ, Ashley S, Tidy A, Smith IE, Dowsett M. Twenty-year follow-up of the Royal Marsden randomized, double-blinded tamoxifen breast cancer prevention trial. J Natl Cancer Inst. 2007 Feb 21;99(4):283-90.

18. Cuzick J, Sestak I, Cawthorn S et al; IBIS-I Investigators. Tamoxifen for prevention of breast cancer: extended long-term follow-up of the IBIS-I breast cancer prevention trial. Lancet Oncol. 2015 Jan;16(1):67-75.

19. Cuzick J, Forbes JF, Sestak I et al. (2007). Long-Term Results of Tamoxifen Prophylaxis for Breast Cancer - 96-Month Follow-up of the Randomized IBIS-I Trial. JNCI 99: 272282.

20. Martino S, Cauley JA, Barrett-Connor E et al; CORE Investigators. Continuing outcomes relevant to Evista: breast cancer incidence in postmenopausal osteoporotic women in a randomized trial of raloxifene. J Natl Cancer Inst. 2004 Dec 1;96(23):1751-61.

21. Barrett-Connor E, Mosca L, Collins P et al; Raloxifene Use for The Heart (RUTH) Trial Investigators. Effects of raloxifene on cardiovascular events and breast cancer in postmenopausal women. N Engl J Med. 2006 Jul 13;355(2):125-37.

22. Vogel VG, Costantino JP, Wickerham DL et al; National Surgical Adjuvant Breast and Bowel Project (NSABP). Effects of tamoxifen vs raloxifene on the risk of developing invasive breast cancer and other disease outcomes: the NSABP Study of Tamoxifen and Raloxifene (STAR) P-2 trial. JAMA. 2006 Jun 21;295(23):2727-41.

23. LaCroix AZ, Powles T, Osborne CK et al; PEARL Investigators. Breast cancer incidence in the randomized PEARL trial of lasofoxifene in postmenopausal osteoporotic women. J Natl Cancer Inst. 2010 Nov 17;102(22):1706-15. 
24. Powles TJ, Diem SJ, Fabian CJ et al. Breast cancer incidence in postmenopausal women with osteoporosis or low bone mass using arzoxifene. Breast Cancer Res Treat. 2012 Jul;134(1):299-306.

25. Dowsett M, Cuzick J, Ingle J et al. Meta-analysis of breast cancer outcomes in adjuvant trials of aromatase inhibitors versus tamoxifen. J Clin Oncol. 2010 Jan 20;28(3):509-18.

26. Cuzick J. Aromatase inhibitors for breast cancer prevention. J Clin Oncol. 2005 Mar 10;23(8):1636-43.

27. Goss PE, Ingle JN, Alés-Martínez JE et al; NCIC CTG MAP.3 Study Investigators. Exemestane for breast-cancer prevention in postmenopausal women. N Engl J Med. 2011 Jun 23;364(25):2381-91.

28. Cuzick J, Sestak I, Forbes JF et al. 2014. On behalf of the IBIS-II investigators. Anastrozole for prevention of breast cancer in high-risk postmenopausal women (IBIS-II): an international, double-blind, randomised placebo-controlled trial. Lancet, 2014 Mar 22;383(9922):1041-8. PMID: 24333009

29. Forbes GM. Colorectal cancer screening tests: pros and cons, and for whom? Expert Rev Gastroenterol Hepatol. 2008 Apr;2(2):197-205.

30. Rothwell PM, Wilson M, Elwin CE et al. 2010. Long-term effect of aspirin on colorectal cancer incidence and mortality: 20-year follow-up of five randomised trials. Lancet, 376: 17411750. PMID: 20970847

31. Algra AM, Rothwell PM. 2012. Effects of regular aspirin on long-term cancer incidence and metastasis: a systematic comparison of evidence from observational studies versus randomised trials. Lancet Oncol, 13: 518-527.

32. Bosetti C, Rosato V, Gallus S et al. Aspirin and cancer risk: a quantitative review to 2011. 2012. Ann Oncol, 23: 1403-1415. PMID: 22517822 
33. Thorat MA, Cuzick J. 2015. Prophylactic use of aspirin: systematic review of harms and approaches to mitigation in the general population. Eur J Epidemiol, Jan;30(1):518. PMID: 25421783

34. Rothwell PM, Wilson M, Price JF, Belch JF, Meade TW, Mehta Z. Effect of daily aspirin on risk of cancer metastasis: a study of incident cancers during randomised controlled trials. Lancet. 2012 Apr 28;379(9826):1591-601. doi: 10.1016/S0140-6736(12)60209-8. Epub 2012 Mar 21.

35. Cook NR, Lee IM, Zhang SM et al. 2013. Alternate-day, low-dose aspirin and cancer risk: long-term observational follow-up of a randomized trial. Ann Intern Med, 159: 77-85. PMCID: PMC3713531

36. Mills EJ, Wu P, Alberton M et al. 2012. Low-dose aspirin and cancer mortality: a meta-analysis of randomized trials. Am J Med, 125: 560-567. PMID: 22513195

37. Chan AT, Ogino S, Fuchs CS. 2009. Aspirin use and survival after diagnosis of colorectal cancer. JAMA, 302: 649-658. PMCID: PMC2848289.

38. Holmes MD, Chen WY, Li L et al. 2010. Aspirin intake and survival after breast cancer. J Clin Oncol, 28: 1467-1472. PMCID: PMC2849768.

39. Langley RE, Burdett S, Tierney JF et al. 2011. Aspirin and cancer: has aspirin been overlooked as an adjuvant therapy? Br J Cancer, Oct 11;105(8):1107-13.

40. Chan AT, Giovannucci EL, Meyerhardt JA et al. 2005. Long-term use of aspirin and nonsteroidal anti-inflammatory drugs and risk of colorectal cancer. JAMA, Aug 24;294(8):914-23. PMCID: PMC1550973.

41. Shebl FM, Hsing AW, Park Y et al, 2014. Non-steroidal anti-inflammatory drugs use is associated with reduced risk of inflammation-associated cancers: NIH-AARP study. PLoS One, Dec 31;9(12):e114633.

42. Bodmer M, Meier C, Krähenbühl S, Jick SS, Meier CR. Long-term metformin use is associated with decreased risk of breast cancer.Diabetes Care. 2010 Jun;33(6):1304-8. 
43. Golozar A, Liu S, Lin JA, Peairs K, Yeh HC. Does Metformin Reduce Cancer Risks? Methodologic Considerations. Curr Diab Rep. 2016 Jan;16(1):4.

44. Gandini S, Puntoni M, Heckman-Stoddard BM et al. Metformin and cancer risk and mortality: a systematic review and meta-analysis taking into account biases and confounders. Cancer Prev Res (Phila). 2014 Sep;7(9):867-85. doi: 10.1158/1940-6207.CAPR-13-0424. Epub 2014 Jul 1.

45. Pollak M. Metformin and other biguanides in oncology: advancing the research agenda. Cancer Prev Res (Phila). 2010 Sep;3(9):1060-5.

46. Naithani R, Huma LC, Moriarty RM, McCormick DL, Mehta RG. Comprehensive review of cancer chemopreventive agents evaluated in experimental carcinogenesis models and clinical trials. Curr Med Chem. 2008;15(11):1044-71.

47. Szabo E. Biomarkers in phase I-II chemoprevention trials: lessons from the $\mathrm{NCl}$ experience. Ecancermedicalscience. 2015 Nov 24;9:599.

48. Negri E, La Vecchia C, Franceschi S, D'Avanzo B, Parazzini F. Vegetable and fruit consumption and cancer risk. Int J Cancer. 1991 May 30;48(3):350-4.

49. Lenzi M, Fimognari C, Hrelia P. Sulforaphane as a promising molecule for fighting cancer. Cancer Treat Res. 2014;159:207-23.

50. Mills PK, Beeson WL, Phillips RL, Fraser GE. Cohort study of diet, lifestyle, and prostate cancer in Adventist men. Cancer 1989;64:598-604.

51. Key TJ, Appleby PN, Travis RC et al; Endogenous Hormones Nutritional Biomarkers Prostate Cancer Collaborative Group. Carotenoids, retinol, tocopherols, and prostate cancer risk: pooled analysis of 15 studies. Am J Clin Nutr. 2015 Nov;102(5):1142-57.

52. Zheng J, Zhou Y, Li Y, Xu DP, Li S, Li HB. Spices for Prevention and Treatment of Cancers. Nutrients. 2016 Aug 12;8(8). pii: E495. 
53. Devassy JG, Nwachukwu ID, Jones PJ. Curcumin and cancer: barriers to obtaining a health claim. Nutr Rev. 2015 Mar;73(3):155-65.

54. Hackshaw-McGeagh LE, Perry RE, Leach VA et al. A systematic review of dietary, nutritional, and physical activity interventions for the prevention of prostate cancer progression and mortality. Cancer Causes Control. 2015 Nov;26(11):1521-50.

55. Vang $\mathrm{O}$, Ahmad N, Baile CA et al. What is new for an old molecule? Systematic review and recommendations on the use of resveratrol. PLoS One.2011;6(6):e19881.

56. Gescher A, Steward WP, Brown K. Resveratrol in the management of human cancer: how strong is the clinical evidence? Ann N Y Acad Sci. 2013 Jul; 1290:12-20.

57. Li MJ, Yin YC, Wang J, Jiang YF. Green tea compounds in breast cancer prevention and treatment. World J Clin Oncol. 2014 Aug 10;5(3):520-8.

58. Malik A, Afaq F, Sarfaraz S, Adhami VM, Syed DN, Mukhtar H. Pomegranate fruit juice for chemoprevention and chemotherapy of prostate cancer. Proc Natl Acad Sci U S A. 2005 Oct 11;102(41):14813-8.

59. Bjelakovic G, Gluud LL, Nikolova D et al. Vitamin D supplementation for prevention of cancer in adults. Cochrane Database Syst Rev. 2014 Jun 23;(6):CD007469.

60. Sporn MB, Dunlop NM, Newton DL, Smith JM. Prevention of chemical carcinogenesis by vitamin A and its synthetic analogs (retinoids). Fed Proc 1976;35:1332 - 8 .

61. Peto R, Doll R, Buckley JD, Sporn MB. Can dietary beta-carotene materially reduce human cancer rates? Nature. 1981 Mar 19;290(5803):201-8.

62. Blot WJ, Li JY, Taylor PR et al. Nutrition intervention trials in Linxian, China: Supplementation with specific vitamin/mineral combinations, cancer incidence, and disease specific mortality in the general population. JNCI. 1993 85:1483-1492. 
63. Omenn GS, Goodman GE, Thornquist MD et al. Effects of a combination of beta carotene and vitamin A on lung cancer and cardiovascular disease. N Engl J Med. 1996 May 2;334(18):1150-5.

64. Albanes D, Heinonen OP, Taylor PR et al. Alpha-Tocopherol and beta-carotene supplements and lung cancer incidence in the alpha-tocopherol, beta-carotene cancer prevention study: effects of base-line characteristics and study compliance. J Natl Cancer Inst. 1996 Nov 6;88(21):1560-70

65. Druesne-Pecollo N, Latino-Martel P, Norat T et al. Beta-carotene supplementation and cancer risk: a systematic review and metaanalysis of randomized controlled trials. . Int J Cancer. 2010 Jul 1;127(1):172-84.

66. Klein EA, Thompson IM Jr, Tangen CM et al. Vitamin E and the risk of prostate cancer: the Selenium and Vitamin E Cancer Prevention Trial (SELECT). JAMA. 2011 Oct 12;306(14):1549-56.

67. Jiang L, Yang KH, Tian JH. Efficacy of antioxidant vitamins and selenium supplement in prostate cancer prevention: a meta-analysis of randomized controlled trials. Nutr Cancer. 2010;62(6):719-27.

68. Pais R, Dumitraşcu DL. Do antioxidants prevent colorectal cancer? A meta-analysis. Rom J Intern Med. 2013 Jul-Dec;51(3-4):152-63.

69. Bjelakovic G, Nikolova D, Gluud LL, Simonetti RG, Gluud C. Antioxidant supplements for prevention of mortality in healthy participants and patients with various diseases. Cochrane Database Syst Rev. 2012 Mar 14;(3):CD007176.

70. Thompson IM Jr, Goodman PJ, Tangen CM et al. 2013. Long-term survival of participants in the prostate cancer prevention trial. N Engl J Med, 369: 603-10. PMCID: PMC4141537. 
71. Andriole GL, Bostwick DG, Brawley OW et al and the REDUCE Study Group. 2010. Effect of dutasteride on the risk of prostate cancer. N Engl J Med, 362: 1192-202. PMID: 20845533.

72. Pinsky PF, Black A, Grubb R et al. Projecting prostate cancer mortality in the PCPT and REDUCE chemoprevention trials. Cancer. 2013 Feb 1;119(3):593-601. doi: 10.1002/cncr.27774. Epub 2012 Aug 14.

73. Cholesterol Treatment Trialists' (CTT) Collaboration, Emberson JR, Kearney PM, Blackwell L et al. Lack of effect of lowering LDL cholesterol on cancer: meta-analysis of individual data from 175,000 people in 27 randomised trials of statin therapy. PLoS One. 2012;7(1):e29849.

74. Parkin DM, Boyd L, Walker LC. 2011. The fraction of cancer attributable to lifestyle and environmental factors in the UK in 2010. Br J Cancer, Dec 6;105 Suppl 2:S77-81. PMCID: PMC3252065.

75. Thun MJ, Jacobs EJ, Patrono C. 2012. The role of aspirin in cancer prevention. Nat Rev Clin Oncol, Apr 3;9(5):259-67.

76. Tyrer J, Duffy SW \& Cuzick J. 2004. A breast cancer prediction model incorporating familial and personal risk factors. Statist. Med, 23: 1111-1130. PMID: 15057881.

77. Gail MH, Brinton LA, Byar DP et al. 1989. Projecting individualized probabilities of developing breast cancer for white females who are being examined annually. Journal of the National Cancer Institute, 81:1879 -1886. PMID: 2593165.

78. McCormack VA, dos Santos Silva I. Breast density and parenchymal patterns as markers of breast cancer risk: a meta-analysis. Cancer Epidemiol Biomarkers Prev. 2006 Jun;15(6):1159-69. 
79. Brentnall AR, Evans DG, Cuzick J. Distribution of breast cancer risk from SNPs and classical risk factors in women of routine screening age in the UK. Br J Cancer. 2014 Feb 4;110(3):827-8.

80. Cuzick J, Warwick J, Pinney E et al. Tamoxifen-induced reduction in mammographic density and breast cancer risk reduction: a nested case-control study. J Natl Cancer Inst. 2011 May 4;103(9):744-52.

81. IARC Working Group on the Evaluation of Cancer-Preventive Strategies. Weight control and physical activity. In H Vainio, F Biachini (eds). IARC Handbooks of Cancer Prevention. Volume 6. Lyon, France. IARC Press. 2002. 60.

82. Chubak J, Whitlock EP, Williams SB, Kamineni A, Burda BU, Buist DS, Anderson ML. Aspirin for the Prevention of Cancer Incidence and Mortality: Systematic Evidence Reviews for the U.S. Preventive Services Task Force. Ann Intern Med. 2016 Jun 21;164(12):814-25.

83. IARC working group on vitamin D. Vitamin D and cancer. WHO press, Geneva, 2008.

84. Lee O, Khan SA Novel routes for administering chemoprevention: local transdermal therapy to the breasts. Semin Oncol. 2016 Feb;43(1):107-15. 


\section{Tables}

Table 1. Established methods for cancer prevention

\begin{tabular}{|c|c|c|c|c|}
\hline Agent & Type of study & $\begin{array}{l}\text { Relevant } \\
\text { studies }\end{array}$ & $\begin{array}{l}\text { Number } \\
\text { evaluated }\end{array}$ & Key findings \\
\hline \multicolumn{5}{|l|}{ Surgery } \\
\hline $\begin{array}{l}\text { Colectomy for } \\
\text { polyposis coli }\end{array}$ & $\begin{array}{l}\text { Danish nation } \\
\text { cohort }\end{array}$ & $\begin{array}{l}\text { Bisgaard }^{1} \\
\text { Half }^{2}\end{array}$ & & $\begin{array}{l}\text { Surgery almost } 100 \% \\
\text { effective if before } \\
\text { cancer }\end{array}$ \\
\hline $\begin{array}{l}\text { Oophorectomy } \\
\text { for BRCA mutant } \\
\text { carriers }\end{array}$ & $\begin{array}{l}\text { Expert review of } \\
\text { cohorts }\end{array}$ & Guillem $^{4}$ & & $\begin{array}{l}100 \% \text { for ovary } \\
\sim 50 \% \text { for breast }\end{array}$ \\
\hline $\begin{array}{l}\text { Bilateral } \\
\text { Mastectomy for } \\
\text { BRCA mutant } \\
\text { carriers }\end{array}$ & $\begin{array}{l}\text { Meta -analysis of } \\
\text { cohorts }\end{array}$ & Ludwig $^{5}$ & & 90-95\% effective \\
\hline HPV vaccination & $\begin{array}{l}3 \text { major RCTs of } \\
\text { VLP based } \\
\text { vaccines }(16,18) \text {, } \\
(6,11,16,18) \text {, } \\
(6,11,16,18,31 \\
33,45,52,58)\end{array}$ & $\begin{array}{l}\text { Paavonen }^{8} \\
\text { Ault }^{7} \\
\text { Joura }^{9}\end{array}$ & 43442 & $\begin{array}{l}>95 \% \text { protection } \\
\text { against CIN lesions due } \\
\text { to vaccine types if given } \\
\text { before infection. Some } \\
\text { cross protection } \\
\text { against other HPV } \\
\text { types. }\end{array}$ \\
\hline HPB Vaccination & $\begin{array}{l}\text { Taiwan National } \\
\text { cohort }\end{array}$ & Chang $^{10}$ & $\begin{array}{l}1509 \text { cases } \\
\text { of HCC of } \\
\text { which } 166 \\
\text { vaccinated }\end{array}$ & $\begin{array}{l}76 \% \text { reduction of } \\
\text { hepatocellular cancer } \\
\text { in those vaccinated }\end{array}$ \\
\hline \multicolumn{5}{|l|}{$\begin{array}{l}\text { Pharmaceutical } \\
\text { agents }\end{array}$} \\
\hline Aspirin & $\begin{array}{l}\text { RCTs and } \\
\text { observational } \\
\text { studies }\end{array}$ & $\begin{array}{l}\text { Rothwell }^{30} \\
\text { Algra }^{31} \\
\text { Bosetti }^{32} \\
\text { Cuzick }^{28}\end{array}$ & $\begin{array}{l}69224 \mathrm{RCT} \\
52926 \mathrm{CC}\end{array}$ & $\begin{array}{l}7-10 \% \text { reduction in all } \\
\text { cancer incidence and 9- } \\
12 \% \text { in mortality in 10y } \\
\text { users. Mostly } \\
\text { colorectal, gastric and } \\
\text { oesophageal cancer } \\
\text { ( } 30 \% \text { each) with } \\
\text { smaller and less certain } \\
\text { reductions in breast, } \\
\text { prostate and lunf } \\
(5=15 \%)\end{array}$ \\
\hline \multicolumn{5}{|l|}{$\begin{array}{l}\text { Anti-oestrogen } \\
\text { compounds }\end{array}$} \\
\hline \multicolumn{5}{|l|}{ SERMs } \\
\hline Tamoxifen & $\begin{array}{l}4 \text { RCTs in high risk } \\
\text { women }\end{array}$ & $\begin{array}{l}\text { Powles, } \\
\text { Fisher,Cuzick, }\end{array}$ & 28193 & $\begin{array}{l}33 \% \text { reduction in all BC } \\
\text { based on } 44 \% \text { of } E R+\end{array}$ \\
\hline
\end{tabular}




\begin{tabular}{|c|c|c|c|c|}
\hline & & $\begin{array}{l}\text { Veronesi as } \\
\text { summarized in } \\
\text { Cuzick }^{16}\end{array}$ & & $\begin{array}{l}\text { invasive and no effect } \\
\text { on ERneg }\end{array}$ \\
\hline Raloxifene & $\begin{array}{l}3 \text { RCTs ( one vs } \\
\text { tamoxifen in high } \\
\text { risk women) }\end{array}$ & $\begin{array}{l}\text { Martino } \\
\text { Barrett- } \\
\text { Connor } \\
\text { Vogel }^{22}\end{array}$ & 37296 & $\begin{array}{l}34 \% \text { reduction overall } \\
\text { with } 56 \% \text { reduction of } \\
\text { ER+ invasive. } \\
25 \% \text { less effective than } \\
\text { tam in direct } \\
\text { comparison in high risk } \\
\text { women }\end{array}$ \\
\hline Lasofoxifene & $\begin{array}{l}1 \mathrm{RCT} \text { in } \\
\text { osteoporotic } \\
\text { women }\end{array}$ & LaCroix $^{23}$ & 8856 & $\begin{array}{l}79 \% \text { reduction in all } B C \\
\text { for higher dose } \\
18 \% \text { reduction for } \\
\text { lower dose }\end{array}$ \\
\hline Arzoxifene & $\begin{array}{l}1 \mathrm{RCT} \text { in } \\
\text { osteoporotic } \\
\text { women }\end{array}$ & Powles $^{24}$ & 9354 & $\begin{array}{l}58 \% \text { reduction for all } \\
B C \\
70 \% \text { reduction for } E R+ \\
B C\end{array}$ \\
\hline \multicolumn{5}{|l|}{$\begin{array}{l}\text { Aromatase } \\
\text { Inhibitors }\end{array}$} \\
\hline Anastrozole & $\begin{array}{l}1 \mathrm{RCT} \text { in high risk } \\
\text { women; } \\
\text { contralateral } \\
\text { tumours in RCTs in } \\
\text { adjuvant setting }\end{array}$ & Cuzick $^{28}$ & 3864 & $\begin{array}{l}53 \% \text { reduction in all } B C \\
58 \% \text { reduction in } E R+ \\
\text { invasive } B C\end{array}$ \\
\hline Exemestane & $\begin{array}{l}1 \mathrm{RCT} \text { in high risk } \\
\text { women; RCT of } \\
\text { contralateral } \\
\text { tumours in } \\
\text { adjuvant setting }\end{array}$ & Goss $^{27}$ & 4560 & $\begin{array}{l}53 \% \text { reduction in all } B C \\
73 \% \text { reduction in } \mathrm{ER}+ \\
\text { invasive } B C\end{array}$ \\
\hline $\begin{array}{l}\text { Oral } \\
\text { Contraceptives }\end{array}$ & $\begin{array}{l}\text { Meta-analysis of } \\
24 \text { case control } \\
\text { and Cohort } \\
\text { studies }\end{array}$ & Havrilesky ${ }^{13}$ & & $\begin{array}{l}27 \% \text { reduction for any } \\
\text { use }>50 \% \text { reduction for } \\
>10 y \text { use }\end{array}$ \\
\hline
\end{tabular}


Table 2. Potential common or major side effects of pharmacologic agents considered for cancer prevention.

\begin{tabular}{|c|c|c|}
\hline Agent & Side effect & Findings \\
\hline \multirow[t]{3}{*}{ Tamoxifen/SERMs } & Endometrial cancer & $\begin{array}{l}2-3 \text { fold increase except for } \\
\text { raloxifene }\end{array}$ \\
\hline & $\begin{array}{l}\text { Venous } \\
\text { thromboembolic } \\
\text { events }\end{array}$ & $\begin{array}{l}73 \% \text { increase overall; smaller } \\
\text { increase with raloxifene }\end{array}$ \\
\hline & $\begin{array}{l}\text { Vasomotor } \\
\text { symptoms }\end{array}$ & $\begin{array}{l}20 \% \text { increase during treatment; } \\
\text { no effect subsequently }\end{array}$ \\
\hline \multirow[t]{5}{*}{$\begin{array}{l}\text { Aromatase } \\
\text { Inhibitors }\end{array}$} & Bone Fractures & $\begin{array}{l}50 \% \text { increase in adjuvant trials } \\
\text { without baseline bone density } \\
\text { scan; NS } 11 \% \text { increase in } \\
\text { prevention studies with baseline } \\
\text { identification and treatment of } \\
\text { women with low bone density }\end{array}$ \\
\hline & $\begin{array}{l}\text { Musculoskeletal } \\
\text { symptoms/ } \\
\text { arthralgia }\end{array}$ & $\begin{array}{l}\text { Increase from } 58 \% \text { in placebo to } \\
64 \% \text { with anastrozole }(10 \% \\
\text { relative increase }\end{array}$ \\
\hline & $\begin{array}{l}\text { Carpal tunnel } \\
\text { syndrome }\end{array}$ & $\begin{array}{l}3.6 \text { fold increase in adjuvant } \\
\text { setting vs tamoxifen ( } 3 \% \text { v } 1 \% \text { ) } \\
58 \% \text { increase ( } 3 \% \text { vs } 2 \% \text { in } \\
\text { prevention }\end{array}$ \\
\hline & $\begin{array}{l}\text { Vasomotor } \\
\text { symptoms }\end{array}$ & $\begin{array}{l}15 \% \text { increase overall; } 20 \% \\
\text { increase in severe symptoms }\end{array}$ \\
\hline & $\begin{array}{l}\text { Vaginal dryness/ } \\
\text { Dyspareunia/Libido } \\
\text { loss }\end{array}$ & $\begin{array}{l}20 \% \text { increase ( } 19 \% \text { v } 16 \%) \\
\text { prevention setting vs placebo ( } 3 \text { - } \\
\text { fold increase vs tamoxifen in } \\
\text { adjuvant setting ( } 1 \% \text { v } 0.3 \%)\end{array}$ \\
\hline \multirow[t]{2}{*}{ Aspirin/ NSAIDs } & $\begin{array}{l}\text { Gastrointestinal } \\
\text { bleeding }\end{array}$ & $\begin{array}{l}\text { Increase of about } 50 \% \text {, mostly in } \\
\text { initial period after starting } \\
\text { treatment. }\end{array}$ \\
\hline & $\begin{array}{l}\text { Haemorrhagic } \\
\text { Stroke }\end{array}$ & $\begin{array}{l}35 \% \text { increase, but larger } \\
\text { reduction in occlusive stokes } \\
\text { Net decrease in incidence but } \\
\text { increase in fatal events }\end{array}$ \\
\hline
\end{tabular}


Figure 1. Long term effect of tamoxifen on breast cancer prevention in the IBIS-I trial. From Cuzick $^{28}$ et al Lancet Oncology 2014.

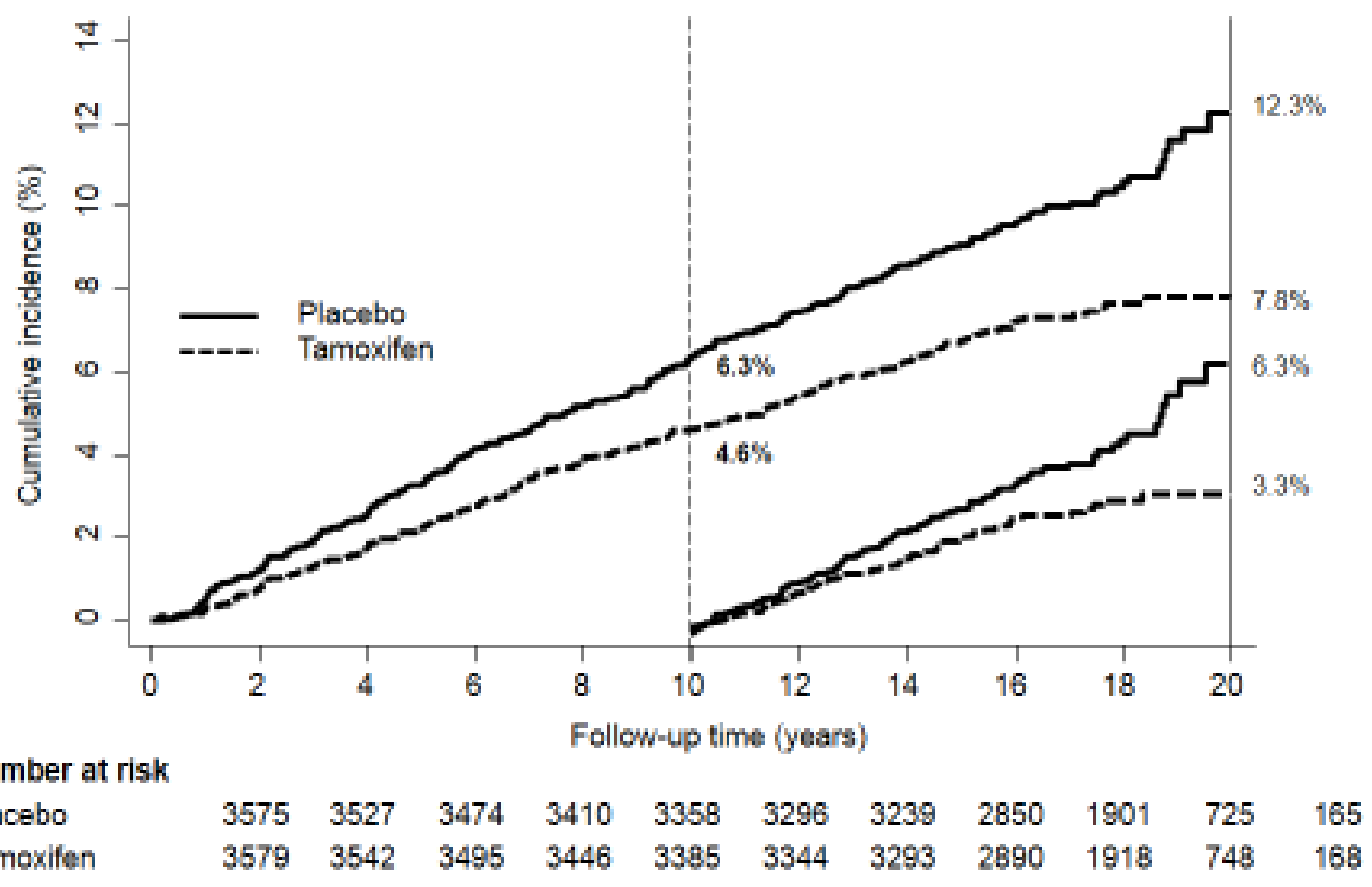


Figure 2. Impact of aspirin on cancer mortality by scheduled duration of treatment. From Rothwell ${ }^{30}$ et al 2011.

1-4.9 years

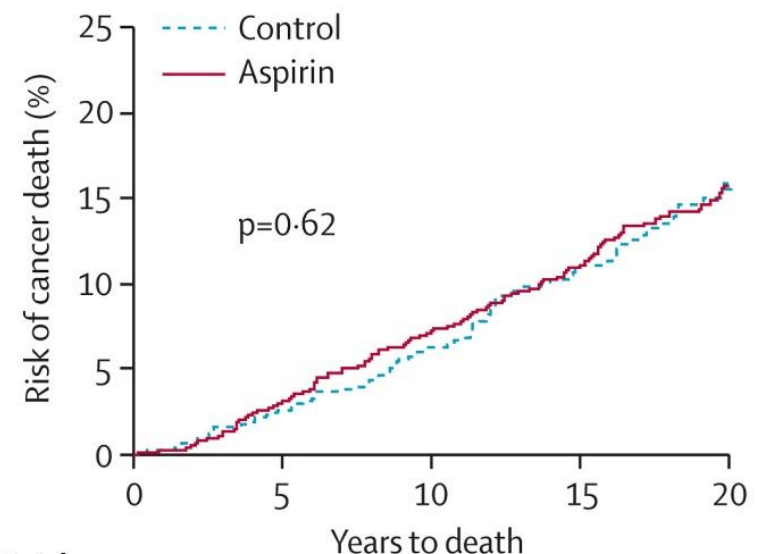

Number at risk

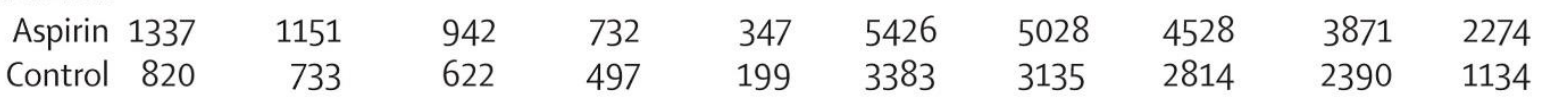

$\geq 7 \cdot 5$ years

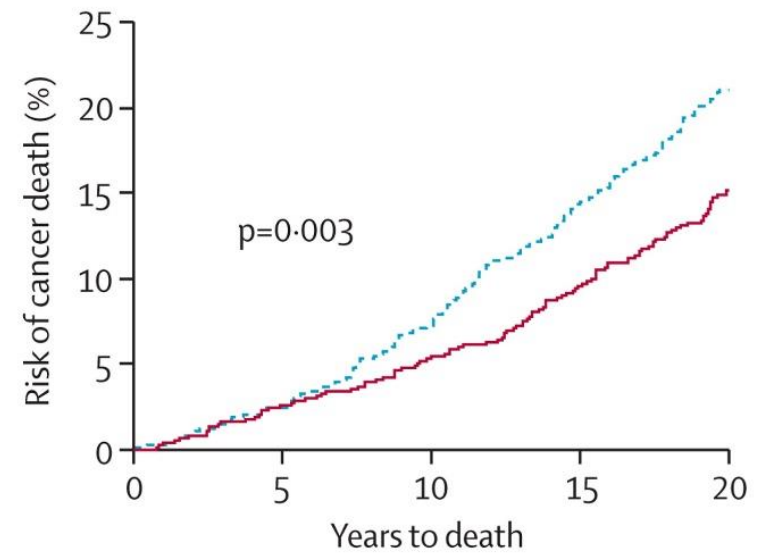

Number at risk

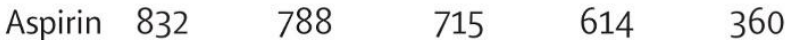

Control 861

$813 \quad 731$

$616 \quad 359$

\section{5-7.4 years}

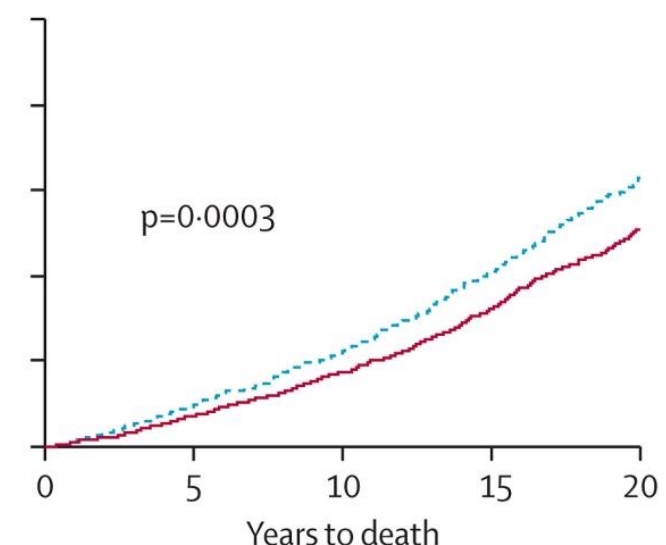

$\begin{array}{lllll}3383 & 3135 & 2814 & 2390 & 1134\end{array}$

All patients

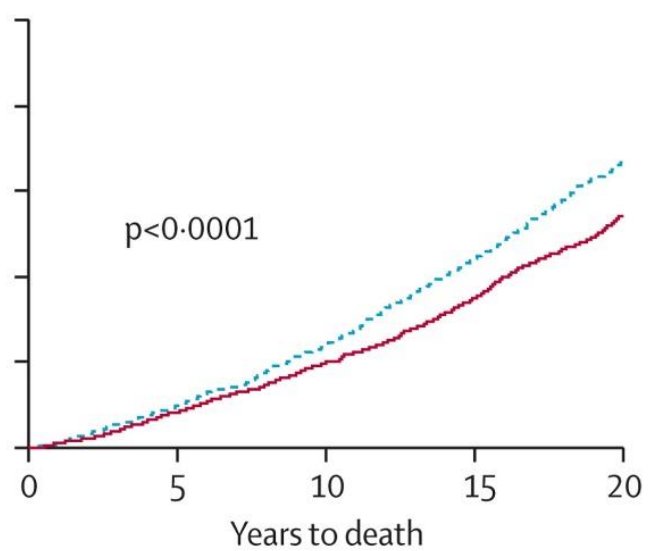

$\begin{array}{lllll}7595 & 6967 & 6185 & 5217 & 2981\end{array}$

$\begin{array}{lllll}5064 & 4681 & 4167 & 3503 & 1692\end{array}$ 